\title{
The diagnosis of left ventricular assist device thrombosis
}

\author{
H.Z.R. Gerds • J. Brügemann • M. Rienstra • M.E. Erasmus
}

Published online: 4 June 2015

(C) The Author(s) 2015. This article is published with open access at Springerlink.com

\begin{abstract}
The clinical course of a patient with a left ventricular assist device is described. A total of 6 weeks after device insertion, the lactate dehydrogenase (LDH) level increased to $2801 \mathrm{U} / 1$ despite adding low-molecular-weight heparin to acenocoumarol and aspirin. Pump thrombosis was suspected but unconfirmed by computed tomography. Increased pump power requirement did not occur. Instituting unfractionated heparin caused a drop in the LDH level. After discontinuing heparin, the LDH levels rose to $5529 \mathrm{U} / 1$ whereupon pump replacement was performed. LDH levels, combined with clinical deterioration and right heart catheterisation, led to the diagnosis of pump thrombosis.
\end{abstract}

Keywords Left ventricular assist device $\cdot$ Heart transplantation $\cdot$ Pump thrombosis

\section{Introduction}

Implantation of a permanent left ventricular assist device (LVAD) in a patient with cardiogenic shock must be avoided. Short-term external left ventricular support and appropriate pharmacological treatment can be a feasible alternative [1, 2]. Mechanical circulatory support by an implantable device is, however, the current therapy of choice for patients who deteriorate clinically while on the waiting list for a heart transplant [3]. Well-known complications after insertion of an LVAD are bleeding, right ventricular dysfunction, (drive-

H.Z.R. Gerds $(\bowtie) \cdot J$. Brügemann · M. Rienstra · M.E. Erasmus Thorax Center UMC Groningen,

Groningen, The Netherlands

e-mail: h.z.r.gerds-ploeger@umcg.nl line) infection, arrhythmias and pump thrombosis [4]. The incidence of pump thrombosis was reported in a range of $1.4-4 \%$ in 2010 [5]. We report a case of early postoperative pump thrombosis.

A 46-year-old man with dilated cardiomyopathy and end-stage heart failure, despite optimal medical and implantable cardioverter defibrillator therapy, was accepted on the Eurotransplant waiting list for heart transplant on May 2013. In July 2013, due to clinical deterioration, he received - in a non-emergency setting - an LVAD type HeartMate II (Thoratec Corp. Pleasanton CA, USA) as a bridge to transplantation [Fig. 1, label 1]. Postoperative recovery was without complications, and the patient was discharged to a cardiac rehabilitation centre 19 days after insertion of the device. In all, 27 days after implantation, the level of lactate dehydrogenase (LDH) increased from $254 \mathrm{U} / 1$ (pre-VAD) to 704 and $1050 \mathrm{U} / 1$ [Fig. 1, label 2]. This raised the suspicion of pump thrombosis and lowmolecular-weight heparin was added to International Normalized Ratio (INR)-guided (1.5-2.5) acenocoumarol and $100 \mathrm{mg}$ of aspirin daily. However, the LDH levels further increased to $2801 \mathrm{U} / 1$ [Fig. 1, label 3]. The patient was hospitalised. Although computed tomography (CT) using contrast showed no signs of obstruction in the VAD circuit and LVAD power requirement did not increase [Fig. 1, label 3], unfractionated heparin (target Activated Partial Thromoplastin Time (APTT) level 40-60 s) was given intravenously. This led to a drop in the LDH level to $778 \mathrm{U} / 1$ [Fig. 1, label 4]. The patient was discharged, but within a few days he complained of fatigue, dyspnoea and reduced exercise tolerance. On re-admission, echocardiography showed an aortic valve opening at each contraction, which was observed more often than in previous echocardiographies. There were no signs of aortic valve regurgitation. Right ventricular function was impaired, indicated by a tri- 
Fig. 1 Lactate dehydrogenase (LDH) level (primary Y axis), haemoglobin (secondary $\mathrm{Y}$ axis) and left ventricular assist device pump power (secondary $\mathrm{Y}$ axis) during follow-up. Numbers 1-6 (top of figure) correspond with the numbers in the text

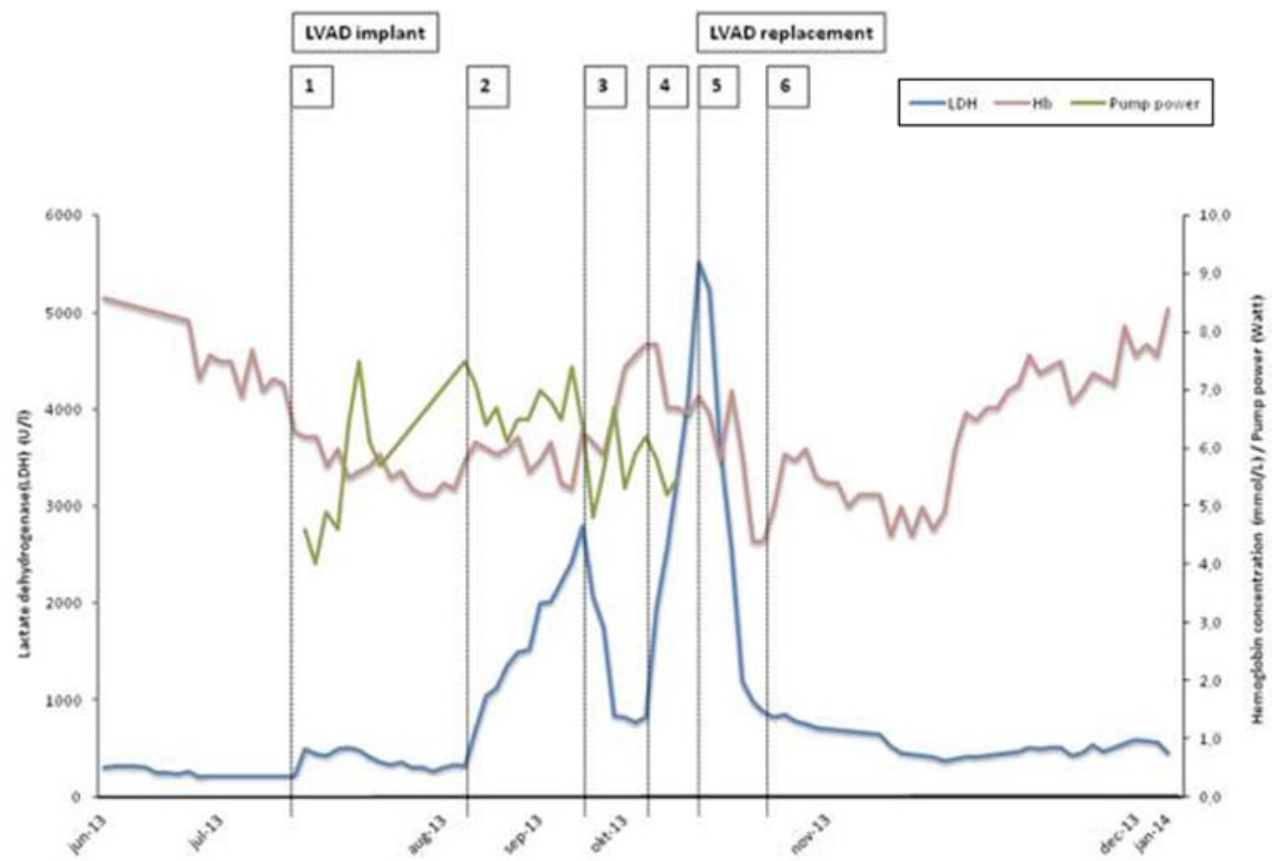

cuspid annulus plane systolic excursion of $10 \mathrm{~mm}$. A velocity of the tricuspid annular systolic motion s'RV of $5.3 \mathrm{~cm} / \mathrm{s}$ was more impaired than earlier. Pump power requirement remained unaltered. The LDH level rose to $1967 \mathrm{U} / 1$ [Fig. 1, label 5]. No lung embolisms or LVAD obstructions were found by repeated contrast CT. Right heart catheterisation showed a cardiac output of $2.96 \mathrm{l} / \mathrm{min}$, which was less than the pre-LVAD calculation of $4.45 \mathrm{l} / \mathrm{min}$. Besides our suspicion of LVAD thrombosis, we ruled out right ventricular overload by reducing pump speed with 400 rotations/min. Sildenafil and milrinone were added to the medication in an attempt to improve right ventricular function but did not lead to clinical or biochemical improvement. In contrast, LDH rose to $5529 \mathrm{U} / 1$ [Fig. 1, label 6]. Since we had no other possible explanation than pump thrombosis, we replaced the LVAD next day using the subcostal approach and found a thrombus localised on the bearing of the inlet cannula (Fig. 2). Clopidogrel replaced aspirin, and the target INR level was raised to $2.5-3.5$ by means of home monitoring. The patient recovered and was discharged first to the cardiac rehabilitation centre and then home. Currently (28 April 2014) the LDH level is $404 \mathrm{U} / 1$.

\section{Discussion}

Our patient demonstrates that the diagnosis of LVAD thrombus can be difficult because of discrepancies in biochemical, echocardiographic and LVAD diagnostics. First, the initially raised $\mathrm{LDH}$ concentrations could have also been a marker of haemolysis instead of thrombosis since the haemoglobin decreased from 7.7 to $4.4 \mathrm{mmol} / \mathrm{l}$. Second, the pump

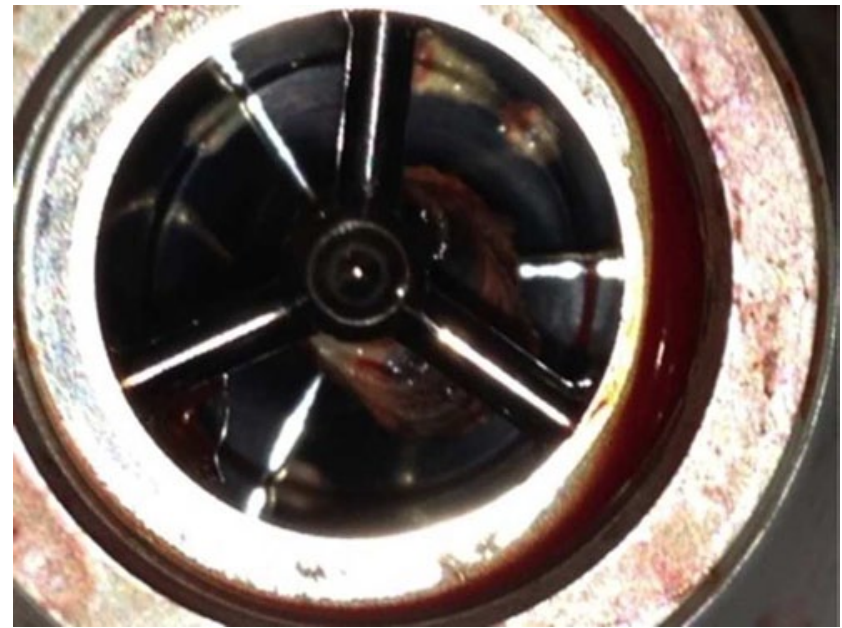

Fig. 2 Thrombus localised on the bearing of the inlet cannula

power requirement was more or less constant in the interval between LVAD insertion and exchange. Third, subsequent echocardiography (eight recordings between first LVAD and the replacement) revealed stable findings. In particular, the frequency of aortic valve opening did not increase during follow-up, except directly before LVAD replacement. Finally, repeated contrast CTs did not support our clinicaland biochemical-based suspicion of LVAD thrombosis.

Increased power requirement of the pump can be pathognomonic for an impeller thrombus but is absent when a thrombus is localised at a HeartMate II inlet bearing ball [6]. We did not apply the suggested ramp test [7]. An unexpected, abrupt increase in incidence of LVAD thrombosis was reported recently [8]. In 2011, the incidence of con- 
firmed pump thrombosis was $2.2 \%$. By January 2013, this had increased to $8.4 \%$ (95\% confidence interval 5-13.9). In addition, the median time from implantation to thrombosis was 18.6 months, but is now much shorter, i.e. 2.7 months. Six weeks after device insertion, a sharp rise in LDH level closely suggested confirmed pump thrombosis. The exact cause of the increased rate of thrombosis remains unclear. After confirmation of the diagnosis, thrombolytic therapy might be an option [9] but pump replacement can be performed with low mortality [10]. It is crucial to monitor LDH levels, among other parameters, to track pump thrombosis in time [11] and apply the algorithm for the diagnosis and management of suspected pump thrombus [12].

In summary: in a LVAD patient receiving adequate oral anticoagulation and antiplatelet therapy despite no increase in pump power requirement, in the case of LDH increase and decrease after intravenous anticoagulation, the diagnosis of pump thrombosis located at the inlet bearing ball is highly likely. Consequently, only pump exchange is probably life-saving.

Funding None.

Conflict of interest None declared.

Open Access This article is distributed under the terms of the Creative Commons Attribution License which permits any use, distribution, and reproduction in any medium, provided the original author(s) and source are credited.

\section{References}

1. Brugts JJ, Manintveld O, Constantinescu A, et al. Preventing LVAD implantation by early short-term mechanical support and prolonged inodilator therapy: a case series with acute refractory cardiogenic shock treated with veno-arterial extracorporeal membrane oxygenation and optimised medical strategy. Neth Heart J. 2014;22:176-81.
2. Haeck MLA, Hoogslag GE, Rodrigo SF, et al. Treatment options in end-stage heart failure: where to go from here? Neth Heart J. 2012;20:167-75.

3. Feldman D, Pamboukian SV, Teuteberg, et al. The 2013 International Society for Heart and Lung Transplantation guidelines for mechanical circulatory support: executive summary. J Heart Lung Transplant. 2013;32:157-87.

4. Felix SEA, Martina JR, Kirkels JH, et al. Continuous-flow left ventricular assist device support in patients with advanced heart failure: points of interest for the daily management. Eur J Heart Fail. 2012;14:351-6.

5. Slaughter MS, Pagani FD, Rogers JG, et al. Clinical management of continuous-flow left ventricular assist devices in advanced heart failure. J Heart Lung Transplant. 2010;29:S1-39.

6. Mokadam NA, Andrus S, Ungerleider A. Thrombus formation in a Heart Mate II. Eur J Cardiothorac Surg. 2011;39:414.

7. Uriel N, Morrison KA, Garan AR, et al. Development of a novel echocardiography ramp test for speed optimization and diagnosis of device thrombosis in continuous-flow left ventricular assist devices. J Am Coll Cardiol. 2012;60:1764-75.

8. Starling RC, Moazami N, Silvestry SC, et al. Unexpected abrupt increase in left ventricular assist device thrombosis. N Engl J Med. 2014;370:33-40.

9. Schlendorf K, Patel CB, Gehrig T, et al. Thrombolytic therapy for refractory hemolysis related to thrombosis of continuous flow ventricular assist devices. J Card Fail. 2014. doi:10.1016/ j.cardfail2013.12.011.

10. Stulak JM, Cowger J, Haft JW, Romano MA, Aaronson KD, Pagani FD. Device exchange after primary left ventricular assist device implantation: indications and outcomes. Ann Thorac Surg. 2013;95:1262-8.

11. Shah P, Mehta VM, Cowger JA, Aaronson KD, Pagani FD. Diagnosis of hemolysis and device thrombosis with lactate dehydrogenase during left ventricular assist device support. J Heart Lung Transplant. 2014;33:102-4.

12. Goldstein DJ, John R, Salerno C, et al. Algorithm for the diagnosis and management of suspected pump thrombus. J Heart Lung Transplant. 2013;32:667-70. 